УДК 811.134.2'42

ББК 81.472.1-51

DOI: https://doi.org/10.17308/lic.2020.4/3083

\title{
АРГУМЕНТАТИВНЫЕ МАРКЕРЫ В ИСПАНСКОМ ПОЛИТИЧЕСКОМ ДИСКУРСЕ
}

\author{
В. В. Корнева, Е. В. Долбилова \\ Воронежский государственный университет

\section{ARGUMENTATIVE MARKERS IN THE SPANISH POLITICAL DISCOURSE}

\author{
V. V. Korneva, E. V. Dolbilova \\ Voronezh State University
}

\begin{abstract}
Аннотация: статья посвящена изучению особенностей функционирования дискурсивных маркеров в испанском политическом дискурсе как эксплицитных средств актуализации аргументации в речи испанских политиков. Рассматриваются такие важные для ичелей исследования проблемы, как основные подходы к пониманию политического дискурса и к трактовке дискурсивных маркеров. Особое внимание уделяется классификации дискурсивных маркеров аргументации в зарубежной испанистике, описываются основные виды аргументативных маркеров и средства их репрезентации в испанском языке. В качестве материала исследования использовались выступления на заседаниях в Конгрессе депутатов Генеральных Кортесов Испании шести кандидатов на пост главы испанского правительства. Общий объем стенограмм публичных выступлений Леопольда Калво (1981), Фелипе Гонсалеса (1989), Марии Хосе Азнара (1996), Хосе Луиса Сапатеро (2004), Марьяно Рахоя (2016) и Педро Санчеса (2016) составляет 51781 словоупотребление. Методом сплошной выборки в них было выделено 285 случаев употребления аргументативных маркеров. Для анализа языкового материала использовались метод наблюдения, сопоставительный метод, а также метод количественного анализа. В результате проведенного исследования были выявлены частотность и особенности функиионирования разных видов аргументативных маркеров (экспликативов, консекутивов и контраргументативов) в испанском политическом дискурсе и в выступлениях отдельных политических деятелей. Были сделаны выводы о закономерностях использования языковых средств репрезентации отдельных аргументативных маркеров в публичных выступлениях политиков в одинаковых коммуникативно-дискурсивных условиях, о взаимосвязи использования разных аргументативных стратегий, приемов и тактик и языковой личности политика.
\end{abstract}

Ключевые слова: политический дискурс, парламентский дискурс, аргументативный маркер, экспликатив, консекутив, контраргумент, испанский язык.

\begin{abstract}
Spanish political discourse. The discourse markers are used as explicit means of argumentation in the speech of Spanish politicians. The paper discusses mainstream approaches to the political discourse and to the concept of discourse markers. Special attention is paid to the classification of discourse markers of argumentation; main types of these markers and the languages means which function as argumentative markers are described. The study is based on the analysis of speeches made by the six candidates for the position of the Spanish Prime Minister in the Congress of Deputies of the Cortes Generales of Spain. The total amount of transcripts of public speeches made by Leopold Calvo (1981), Felipe Gonzalez (1989), Maria Jose Aznar (1996), Jose Luis Zapatero (2004), Mariano Rajoy (2016) and Pedro Sanchez (2016) is 51781 tokens. By using the method of continuous sampling 285 contexts of use of argumentative discourse markers were found. Other methods used in the research include observations, comparative method and quantitative methods. The results of the research include frequency calculations and conclusions
\end{abstract}

(C) Корнева В. В., Долбилова Е. В., 2020

Контент доступен под лицензией Creative Commons Attribution 4.0 License.

The content is available under Creative Commons Attribution 4.0 License. 
about specific features of various argumentative markers (explicatives, consecutives and counter-argumentatives) in the speeches of Spanish politicians. The authors describe a number of regularities in the use of the argumentative markers in public political speeches in similar conditions and list strategies, tactics and patterns characteristic of the speech manners of various politicians.

Key words: political discourse, parliamentary discourse, argumentative marker, explicative, consecutive, counterargument, the Spanish language.

\section{Введение}

Политический дискурс - явление многоплановое и многоаспектное. Не случайно на рубеже веков в языкознании возникает новое направление - политическая лингвистика, предметом изучения которой как раз-таки и является политический дискурс. При широком понимании данного явления к нему относят «любые речевые образования, адресат или содержание которых относятся к сфере политики» [1, с. 23], а при узком политический дискурс трактуется как «дискурс политиков, реализуемый в виде правительственных документов, парламентских дебатов, партийных программ, речей политиков» [2, p. 13].

Политический дискурс оказывает влияние на общество в большей степени, чем другие типы дискурса, что обусловлено его манипулятивной функцией (см., например, [1; 3-6], и как следствие этого, он вызывает неизменный интерес исследователей. В сфере интересов ученых-лингвистов оказываются следующие проблемы: определение самого феномена «политический дискурс» и сферы его бытования [1; 5]; политический дискурс как особый тип текста, его макро- и микроструктура [4]; вариативность политического дискурса и формы его существования (устный и письменный политический дискурс, среди которых различают парламентский дискурс, предвыборный дискурс и др. [1;7]); дискурсивные стратегии, используемые в политическом дискурсе $[6 ; 8])$; лексико-синтаксические особенности данного типа текста $[7 ; 9])$; метафора в политическом дискурсе [10; 11]; универсальное и культурно-специфическое в политическом дискурсе $[4 ; 5])$ и др. При этом в зависимости от научной школы и направления (к примеру, таких наиболее активно разрабатываемых в последнее время, как функционализм или когнитивно-дискурсивная научная парадигма) в центре внимания исследователей окажутся разные стороны одного и того же аспекта изучения политического дискурса.

Политический дискурс имеет полемический характер, а потому в нем обязательно присутствуют аргументативные компоненты. Более того, некоторые исследователи вообще склонны рассматривать политический дискурс исключительно как аргументативный тип текста, в основе которого лежит аргументация (см., например, [1; 7; 12]). Следует различать аргументацию как категорию логики и как категорию лингвистики.
В логике аргументацию определяют как «логический процесс, в ходе которого истинность какого-либо положения выводится из истинности аргументов» $[13$, с. 13], тогда как в лингвистике сложилось иное понимание данного феномена. В качестве примера приведем определение А. Бриза, в котором подчеркивается, что аргументация - это особый вид деятельности - социальной, умственной и вербальной, которая служит для утверждения и опровержения того или иного довода [14, p. 21].

Практически во всех видах дискурса в процессе интеракции говорящий не только излагает свою точку зрения на то или иное положение дел, но и аргументирует ее, приводит доводы в ее пользу либо против другой точки зрения. Целью аргументации является достижение убежденности аудитории в правомерности (правильности) излагаемых говорящим положений. Аргументация имеет трехчленную структуру и включает в себя тезис, аргумент и вывод (см., например, $[8 ; 15 ; 16])$. Аргумент представляет собой одно или несколько утверждений, раскрывающих, конкретизирующих и подтверждающих тезис. Аргументы, опровергающие тезис, называют контраргументами. И аргументы, и контраргументы представлены в виде коммуникативно достаточных синтаксических структур, которые принято называть аргументативными суждениями. Внутри этих структур, а также между ними используются разного рода слова и словосочетания, которые в широком смысле слова трактуются в современной лингвистике как дискурсивные маркеры, поскольку они служат организации дискурсивной деятельности коммуникантов и в то же время уточняют, конкретизируют смысл высказывания.

Применительно к теме нашего исследования языковые единицы такого рода правомерно называть аргументативными маркерами, поскольку они эксплицируют те или иные компоненты аргументации. Для обозначения этих лексических единиц можно также использовать другой термин - аргументатив.

Изучение дискурсивных маркеров (дискурсивов) имеет длительную историю, однако объем этих единиц и их интерпретация по-прежнему вызывают разногласия. В испанистике, в частности, одни исследователи предпочитают использовать для таких языковых единиц термин дискурсивные коннекторы и выделяют такие его разновидности, как причинные 
коннекторы (conectores de causa), коннекторы следствия (conectores de consecuencia), коннекторы уточнения (conectores de certeza), коннекторы выражения собственного мнения (conectores de propia opinión), оппозитивные коннекторы (conectores de oposición), коннекторы условия (conectores de condición), коннекторы объединения/единства (conectores de unión), порядковые коннекторы (conectores de orden) и коннекторы сходства (conectores de semejanza) (см., например, [17, pp. 58-77]).

Другие ученые не только используют иную терминологию для обозначения одних и тех же явлений, но и расширяют или сужают круг дискурсивных маркеров, зачастую применяя разные критерии для их выделения и анализа. В качестве примера приведем классификацию данных языковых единиц М. Cорракино и Х. Портолес в авторитетнейшем издании академической «Дескриптивной грамматике испанского языка» [18, pp. 4051-4214]. При ее создании они исходят из выполняемых ими дискурсивных функций, которые, по словам авторов, в большей или меньшей степени определяются семантикой, «семантическими свойствами» данных языковых единиц. Исходя из этих теоретических посылок, М. Сорракино и Х. Портолес выделяют пять основных групп дискурсивных маркеров. Одни из них - estructuradores de la información - служат средством организации и структурирования информации в тексте/дискурсе. Другие-conectores - семантически и прагматически связывают компоненты дискурса друг с другим. Третьи - reformuladores - передают содержание предыдущей части дискурса иными словами. Четвертую и пятую группы составляют operadores argumentativos и marcadores conversacionales.

В целом высоко оценивая труд этих ученых, отдельные их теоретические положения требуют комментария и уточнения. Так, обращает на себя внимание разнообразие используемой авторами терминологии и выделяемых ими групп. С одной стороны, они используют в общем-то традиционное для зарубежной испанистики деление дискурсивных маркеров на операторы и коннекторы, в основе которого лежит структурно-синтаксический критерий их функционирования на уровне предложения-высказывания или же на уровне текста/дискурса и отдельных его частей (см., например, [19; 20]). С другой стороны, выделение такой группы дискурсивов, как «разговорные маркеры», основано не на выполняемой ими дискурсивной функции, а на основании сферы их функционирования - устной разговорной речи.

Что касается тех разнообразных языковых единиц, которые эксплицируют разные формы аргументативных суждений, то в классификации дискурсивных маркеров М. Сорракино и Х. Портолеса они оказываются распределенными по разным группам.
Одни из них - conectores consecutivos 'консекутивные коннекторы' $и$ conectores contraargumentativos 'контраргументативные коннекторы' - входят в группу коннекторов. Другие же попадают в группу «аргументативных операторов» и включают в себя операторы усиления аргументации operadores de refuerzo argumentativo' (en realidad, en el fondo, de hecho и др.) и операторы конкретизации 'operadores de concrecion' (por ejemplo, en particular и др.). При этом такие важные для аргументации специализированные средства, которые выражают значение обусловленности/причины того или иного положения дел, вообще выпадают из поля зрения данных ученых.

Обобщая наши наблюдения, отметим следующее. Используемые при аргументации дискурсивные маркеры включают в себя целый ряд достаточно разнородных явлений, которые в испанистике обозначаются терминами «аргументативный коннектор», «аргументативный оператор» и «аргументативный маркер». К аргументативным коннекторам исследователи относят текстообразующие аргументативные средства, функциональным назначением которых является организация дискурса, его макроструктуры. К аргументативным же операторам они относят фразообразующие аргументативы, которые служат организации отдельных частей аргументативного дискурса, будь то части одного предложения-высказывания или их сочетание. В их число входят средства усиления (укрепления), ослабления или уточнения (конкретизации) аргумента (см., например, [18, pp. 40514097]).

В связи вышеизложенным необходимо сделать ряд принципиальных для целей нашего исследования уточнений.

Первое. Правомерно, на наш взгляд, по аналогии с термином «дискурсивные маркеры» или «дискурсивы» использовать термин «аргументативные маркеры» (аргументативы), поскольку языковые средства их выражения указывают на определенный вид логической связи в аргументативной цепочке суждений.

Второе. Выделяемые М. Сорракино и Х. Портолеса операторы усиления аргумента (en realidad, en el fondo, de hecho) и операторы конкретизации аргумента (por ejemplo, en particular) являются не дискурсивными/аргументативными маркерами, а явлениями другого порядка, а именно приемами аргументации. К слову сказать, в проанализированных нами публичных выступлениях испанских политиков прием конкретизации встречается крайне редко, причем используется только одно средство - выражение en particular 'в частности' (М. Х. Азнар использует его 3 раза, Ф. Гонсалес - 2 раза, а Л. Сапатеро - 1 раз), тогда как средства усиления аргументации вовсе не обнаружены. 
Третье. К эксплицитным средствам аргументации в первую очередь относятся языковые средства выражения обусловленности, ядро которой составляют причинно-следственные отношения. В зависимости от семантической функции аргументативов можно выделить такие их разновидности, как экспликативы и консекутивы, а также контраргументы.

Экспликативы (причинные коннекторы, по определению Д. Монастерио), назначение которых заключается в объяснении причины (предположения) того или иного положения дел, в испанском языке выражаются такими языковыми средствами, как роrque, que, puesto que, a causa de que, pues, ya que, visto que, supuesto que, como (см., например, [21, p. 3597]), а также debido a, dado que, por el hecho de que, en virtud de que [17, p. 58].

Консекутивы, напротив, указывают на следствие (логическое или гипотетическое), обусловленное тем или иным положением дел. Для их обозначения испанский язык также располагает большим набором средств: pues, así pues, por tanto, por consiguente, consiguientemente, concecuentemente, por ende, de ahi, en consecuencia, de resultado, así, entonces [18, p. 4099], а также luego, dado que, por eso, de manera que, de donde se desprende, así que, por lo tanto, por lo expuesto, por la razón [17, p. 58].

Отдельную группу составляют контраргументативы. К средствам их репрезентации в испанском языке относятся: en cambio, por el contrario, al contrario, por contra, antes bien, sin embargo, no obstante, con todo, empero, ahora bien, ahora, eso sí и pero, aunque, contrariamente (см., например, [17, p. 58; 18, p. 4109; 22]).

Указанные виды аргументативов как сигналы аргументации наиболее частотны в любом виде дискурса, в том числе и в политическом дискурсе.

\section{Цель и задачи исследования}

Предметом нашего изучения являются маркеры аргументации, используемые известными политическими деятелями Испании в публичных выступлениях в парламенте. Цель нашего исследования заключается в том, чтобы выявить особенности функционирования разных видов аргументов в испанском политическом дискурсе, а также определить, насколько характерны для него разные виды аргументативных маркеров.

Для достижения поставленной цели была предпринята попытка ответить на следующие вопросы.

1. Какие виды аргументативов (экспликативы, консекутивы или контраргументативы) представлены в испанском политическом дискурсе?

2. Какие из них наиболее частотны в публичных выступлениях разных политиков?
3. Какие средства в каждом виде аргументатива наиболее характерны для испанского политического дискурса?

4. Определить, есть ли связь между:

а) дискурсивным контекстом (ситуацией публичного выступления политика) и используемыми аргументативными маркерами (экспликативами, консекутивами и контраргументативами);

б) языковыми средствами выражения того или иного вида аргументатива и языковой личностью политика.

В нашем исследовании мы исходим из того, что выбор и частотность употребления разных видов аргументативов зависят от многих факторов, в том числе от национальных культурно-специфических дискурсивных практик, типа дискурса и языковой личности автора, а также от дискурсивных условий (ситуации) их реализации.

\section{Материал и методы исследования}

Для верификации или опровержения высказанного положения мы обратились к анализу публичных выступлений в Конгрессе ведущих политиков Испании. Материалом для исследования послужили выступления на заседаниях в Конгрессе депутатов Генеральных Кортесов Испании шести кандидатов на пост главы испанского правительства. Среди них выступления Леопольда Калво Сотело (1981), Фелипе Гонсалеса (1989), Марии Хосе Азнара (1996), Хосе Луиса Сапатеро (2004), Марьяно Рахоя (2016), Педро Санчеса (2016). Общий объем официальных стенограмм выступлений указанных политиков составляет 51781 словоупотребление. Методом сплошной выборки в них было выделено 285 случаев употребления аргументативных маркеров. Кроме метода сплошной выборки для анализа указанного языкового материала использовались такие методы, как метод наблюдения, сопоставительный метод, а также метод количественного анализа.

Следует специально оговорить, чем обусловлен выбор именно этих выступлений в качестве материала исследования. Известно, что парламентские выступления (парламентский дискурс) как отдельная разновидность политического дискурса отличаются тем, что они достаточно жестко регламентированы и по времени, и по форме, и в какой-то степени по содержанию. Время выступления в испанском конгрессе, как правило, составляет порядка 10 минут. Устное выступление тщательно готовится заранее. На этапе подготовки оно представлено письменным текстом, однако при выступлении читать его нельзя, разрешается пользоваться лишь отдельными заметками. Известно также, что парламентский дискурс неоднороден по своему составу и включает в себя разные виды 
публичных выступлений (политические дебаты, программные заявления и др.). Именно поэтому мы выбрали такие выступления, которые проходили в одних и тех же коммуникативно-дискурсивных условиях и все выступающие преследовали одну и ту же цель - убедить парламентариев в том, что они - самые достойные кандидатуры на пост главы испанского правительства и что в случае избрания они будут претворять в жизнь политику на благо и процветание всего испанского народа. Для достижения поставленной цели политики используют определенную аргументативную стратегию, включающую в себя целую серию аргументативных приемов и тактик, среди которых важную роль играют аргументативные маркеры.

\section{Виды аргументативных маркеров В испанском политическом дискурсе}

Проведенное нами исследование показало, что испанские политики в своих выступлениях используют все указанные ранее виды аргументативных маркеров - экспликативы, консекутивы и контраргументативы. В то же время диапазон варьирования языковых средств их репрезентации в политическом дискурсе значительно ниже, чем в системе испанского языка. Об этом убедительно свидетельствуют данные табл. 1-3.

Прокомментируем полученные результаты. Как вытекает из приведенных в таблицах данных, существенных различий в использовании аргументативных маркеров в речи испанских политиков не выявлено. Тем не менее в проанализированном материале наблюдается преобладание контраргументативов (109 единиц) при практически одинаковой частотности употребления экспликативов и консекутивов (89 и 87 единиц соответственно). Однако внутри каждого из выделенных видов аргументативных маркеров эти различия достаточно велики. Так, среди всех дискурсивных единиц исследуемой семантики наиболее частотным является экспликатив porque (84), несколько меньше частотность контраргументатива pero (78), тогда как наиболее распро-

Т а б ли ц а 1

Контраргументативы в речи испанских политиков

\begin{tabular}{|l|c|c|c|c|c|c|c|}
\hline \multicolumn{1}{|c|}{ Политик/контраргументатив } & Calvo Sotelo & González & Aznar & Zapatero & Rajoy & Sánchez & Bceго \\
\hline en cambio & & & 1 & & & & 1 \\
\hline por el contrario & 2 & & & 1 & & 3 \\
\hline antes bien & 1 & & & & & & 1 \\
\hline sin embargo & 7 & 2 & 3 & 3 & & & 15 \\
\hline no obstante & & & & 1 & & & 1 \\
\hline con todo & & & 1 & 1 & & & 2 \\
\hline ahora bien & 1 & & & & & & 8 \\
\hline pero & 19 & & 9 & 19 & 23 & & 78 \\
\hline aunque & 4 & 1 & 1 & 1 & & & 7 \\
\hline Bcero & 34 & 3 & 15 & 26 & 23 & 8 & 109 \\
\hline
\end{tabular}

Т а б ли ц а 2

Консекутивы в речи испанских политиков

\begin{tabular}{|l|c|c|c|c|c|c|c|}
\hline \multicolumn{1}{|c|}{ Политик/консекутив } & Calvo Sotelo & González & Aznar & Zapatero & Rajoy & Sánchez & Bceго \\
\hline por ello & 3 & & 1 & 6 & 1 & 11 \\
\hline por tanto & 2 & 7 & & & & 1 & 10 \\
\hline por consiguiente & & 31 & & & & & 31 \\
\hline por la (esta) razón & & & 6 & & & & 6 \\
\hline en concuencia & 1 & & & 4 & 1 & & 5 \\
\hline de ahí & 1 & & & & & & 1 \\
\hline por esto & 1 & & 2 & & & & 3 \\
\hline por eso & 2 & & & 2 & 5 & & 7 \\
\hline por lo que & & & 3 & & & & 3 \\
\hline Bcero & 10 & 38 & 12 & 12 & 7 & 8 & 87 \\
\hline
\end{tabular}


Экспликативы в речи испанских политиков

\begin{tabular}{|l|c|c|c|c|c|c|c|}
\hline Политик/экспликатив & Calvo Sotelo & González & Aznar & Zapatero & Rajoy & Sánchez & Bceго \\
\hline porque & 14 & 9 & 28 & 11 & 17 & 5 & 84 \\
\hline puesto que & & 1 & & & & 1 & 2 \\
\hline уа que & & & 1 & & & & 2 \\
\hline como & & 2 & & & 11 & 5 & 89 \\
\hline Всего & 14 & 12 & 29 & 11 & & 2 \\
\hline
\end{tabular}

страненный консекутив por eso (16) используется в пять раз реже.

Высокая частотность аргументативных маркеров porque, pero и por eso объясняется, на наш взгляд, несколькими причинами. Во-первых, они являются специализированными средствами выражения соответствующей функции и однозначно указывают на нее. Во-вторых, они стилистически нейтральны, а потому общеупотребительны.

Сказанному вовсе не противоречит тот факт, что контраргументатив pero широко используется не только для связи/противопоставления пропозиций или отдельных ее частей (слов и/или синтагм). Не менее широко он используется в начале предложения, благодаря чему контраргумент становится более весомым, а позиция выступающего к излагаемому положению дел - более определенной и однозначной. Ср.:

Y creo que los españoles han confirmado este juicio con sus votos. Pero creo, también, que ha puesto en marcha iniciativas que han contribuido al progreso de España.

(Calvo-Sotelo, 1)

El Gobierno actuará de acuerdo con sus ideas, de acuerdo con su programa, de acuerdo con sus valores. Pero el Gobierno que yo presida tiene también, como proyecto político, la voluntad de incorporar en la toma de decisiones las visiones que se aporten lealmente desde otras perspectivas politicas, y de lograr asi para sus políticas el apoyo más amplio posible de los grupos parlamentarios.

(Calvo-Sotelo, 2)

Аналогичный комментарий можно сделать и относительно экспликатива porque. Ср. приводимые ниже примеры:

Ahi estará España: en la defensa de estos valores. Porque sin dignidad, sin igualdad entre mujeres $y$ hombres, sin respeto a los derechos humanos no habrá ni paz ni desarrollo.

(Sánchez, 3)

Este debe ser el gran objetivo de toda la sociedad española. Porque, señoras y señores diputados, es dolorosamente obligado recordar que España sufre hoy la mayor tasa de paro de la Unión Europea y, a la vez, el mayor porcentaje de empleo precario.

(Aznar, 4)

Porque hay que reconocer que, en los veinticinco años que hemos vivido de Democracia, la sociedad se ha mostrado, en muchas ocasiones, más viva y dinámica que la política.

(Zapatero, 5)

В приведенных выше примерах обращает на себя внимание тот факт, что в официальных стенограммах публичных выступлений указанных ранее политиков графически предложения-высказывания с аргументативными маркерами представлены по-разному. В одних случаях инициальная позиция аргументативного маркера формально (графически) никак не выделяется в тексте и вводимое им аргументативное суждение входит в структуру абзаца (примеры 1-5). В других случаях значимость того или иного аргументативного суждения с инициальной позицией аргументативного маркера определенной семантики выделяется графически, воспроизводя, насколько это возможно, особенности их произношения (звучания) в устной речи политика. Достигается это тем, что предложения-высказывания такого рода оформляются как начало нового абзаца и могут даже отделяться от него пробелом. Ср.:

$Y$ a ese cambio estará dispuesto el Gobierno que yo forme si obtengo la investidura de la Cámara.

Porque el riesgo mayor de nuestra situación sería que atribuyéramos los males que nos afligen a una estructura política determinada. Trataré más bien de elegir un conjunto de problemas preferentes hacia los que desearía llevar este debate de investidura, porque a todos nos importa acertar en ellos, en su solución, y porque creo que para acertar debo estar abierto a los juicios y las opiniones de todos los señores diputados, por diferentes que sean, y lo serán en muchos casos, de los míos.

(Calvo-Sotelo, 6)

Y condenaré toda utilización política del terrorismo.

Porque el elemento esencial de la lucha contra el terrorismo es la unidad de los demócratas.

(Zapatero, 7) 
Другое наблюдение касается возможностей использования отдельных средств репрезентации конкретных видов аргументативных маркеров в публичных выступлениях политиков, которые, повторим, протекают в одинаковых дискурсивных условиях. Как и предполагалось, в нем используются далеко не все аргументативные средства, которыми располагает испанский язык, поскольку политика представляет собой особую сферу человеческой деятельности. Более того, в политическом дискурсе рассматриваемого типа используется в лучшем случае лишь половина аргументативов, и это при том, что многие из них отмечены как единичные случаи в речи отдельных политиков. Фактически же «узаконенными» в данном типе дискурса оказываются всего лишь дватри, а то и одно языковое средство.

Такое положение дел характерно для всех видов рассматриваемых нами аргументативов. В частности, среди экспликативов не отмечены такие единицы, как que, a causa de que, pues, visto que, supuesto que, debido $a$, dado que, por el hecho de que, en virtud de que. Apгументатив сото используется дважды только в речи $\Phi$. Гонсалеса. Аргументатив уа quе также используется дважды, но уже в речи разных политиков М. Х. Азнара (1) и М. Рахоя (1). Наконец, экспликатив puesto que один раз употребил Ф. Гонсалес. Таким образом, из 12 теоретически возможных аргументативных маркеров в речи испанских политиков отмечены только 4. Однако с учетом их крайне низкой частотности, о чем говорилось выше, на практике только экспликатив porque свободно функционирует в данном типе испанского политического дискурса.

Причины такого положения дел кроются в том, что одни из них, а именно como, quе и pues, являются синкретичными и для реализации аргументативного значения нуждаются в поддержке контекста, т. е. для данных языковых единиц оно является контекстно обусловленным. Другие же единицы - a causa de que, visto que, supuesto que-debido a, dado que, por el hecho de que, en virtud de que - хотя и являются однозначными, но носят явно выраженный книжный характер - что также препятствует их использованию в данном виде парламентского дискурса (подробнее о функционально-семантических различиях экспликативов см., например, [22, pp. 220-226; 23, pp. 3599-3656]).

Аналогичные комментарии можно сделать и относительно функционирования других видов аргументативных маркеров в исследуемом типе дискурса. В частности, более чем из двадцати контрагументативов в речи испанских политиков используется менее половины. Однако, как и в случае с экспликативами, часть из них употребляется лишь однажды таковы аргументативные маркеры antes bien и ahora bien, которые употребляет Л. Калво Сотело, а также en cambio в речи М. Х. Азнара и no obstante в высту- плении Х. Л. Сапатеро. В речи только двух политиков отмечены контраргументативы por el contrario (Л. Калво Сотело использует его дважды, а Х. Л. Сапатеро один раз) и con todo (его однократное употребление отмечено в выступлениях М. Х. Азнара и Х. Л. Сапатеро). Таким образом, доля участия вышеуказанных языковых единиц в организации аргументативного дискурсивного пространства ничтожно мала, особенно если учесть, что на долю других контраргументативов (pero, sin embargo и aunque) приходятся 100 случаев употребления из 109. Обращает на себя внимание не только разная частотность этих контраргументативных маркеров (pero 78, sin embargo 15 и aunque 7), но и тот факт, что одни политики используют разные средства выражения контраргумента (особенно это характерно для речи Л. Калво Сотело, Х. Л. Сапатеро и М. Х. Азнара), тогда как в арсенале других, напротив, одно-единственное средство pero. При этом контраргументативный маркер pero активно и чаще всего используют практически все политики, за исключением Ф. Гонсалеса, который, к слову сказать, в своих рассуждениях для аргументации предпочитает использовать не контраргументативы (их у него всего 3), а другой вид аргументативных маркеров - консекутивы (38).

В целом консекутивы в испанском политическом дискурсе также представлены в значительно меньшем объеме по сравнению с тем богатством средств, которым обладает испанский язык. В нем, в частности, не используются следующие языковые единицы: pues, así, así pues, así que, por lo tanto, consiguientemente, concecuentemente, por ende, de resultado, entonces, luego, dado que, de manera que, de donde se desprende, por lo expuesto (о структурно-семантических различиях этих и других консекутивов см., например, [18, pp. 4099-4109; 24, pp. 3739-3804]).

Вместе с тем в использовании других консекутивных маркеров четко прослеживаются языковые пристрастия ораторов. Последние проявляются как в частотности употребления одних языковых единиц по сравнению с другими (как, например, в речи $\Phi$. Гонсалеса консекутив por consiguiente встречается 31 раз из 38, а в выступлении М. Х. Азнара наиболее частотным оказывается консекутив por la (esta) razón - 6 случаев употребления из 12), так и в исключительном выборе определенного консекутива (консекутивы por consiguiente и por la (esta) razón выявлены только в выступлениях вышеуказанных политиков). Наиболее частотными в испанском политическом дискурсе оказываются такие консекутивы, как por eso (16), por ello (11), por tanto (10). Следует специально оговорить, что консекутив por consiguiente встречается в два раза чаще, чем консекутив por eso (31 и 16). Однако он отмечен лишь в одном выступлении - в выступлении Ф. Гонсалеса, а потому мы 
сочли возможным не учитывать его при анализе частотности аргументативных маркеров, а считать проявлением языковой личности оратора.

Из всего сказанного можно сделать следующий вывод. Дискурсивные условия политической коммуникации оказывают определенное влияние на использование коммуникантами тех или иных языковых средств. В испанском политическом дискурсе рассматриваемого типа наблюдается явно выраженная тенденция - если не сказать закономерность в использовании определенных языковых средств как маркеров аргументации. Основным средством выражения разных видов аргументативных маркеров в нем являются наиболее частотные стилистически нейтральные однозначные языковые единицы, бла- годаря использованию которых интеракция коммуникантов в политическом дискурсивном пространстве проходит успешно. К числу этих средств относятся союзы porque, pero и por eso, каждый из которых функционирует как аргументативный маркер определенного вида, будь то экспликатив (porque), контраргументатив (pero) или же консекутив (por eso).

\section{Частотность употребления аргументативных маркеров в речи испанских политиков}

Анализ языкового материала позволяет сделать еще один вывод, основанный на частотности употребления аргументативных маркеров в речи испанских политиков, представленной в табл. 4.

Т а б л и ц а 4

Частотность употребления аргументативных маркеров в речи испанских политиков

\begin{tabular}{|l|c|c|c|c|c|c|c|}
\hline \multicolumn{1}{|c|}{ Политик / аргументативный маркер } & Calvo Sotelo & González & Aznar & Zapatero & Rajoy & Sánchez & Bceго \\
\hline Экспликативы & 14 & 12 & 29 & 11 & 18 & 5 & 89 \\
\hline Консекутивы & 10 & 38 & 12 & 12 & 7 & 8 & 87 \\
\hline Контраргументативы & 34 & 3 & 15 & 26 & 23 & 8 & 109 \\
\hline Всего & 58 & 53 & 56 & 49 & 48 & 21 & 285 \\
\hline
\end{tabular}

Как вытекает из полученных данных, одни политики отдают предпочтение одним аргументативным маркерам, а другие - другим. В частности, в выступлениях Л. Калво Сотело, Л. Сапатеро и М. Рахоя преобладают контраргументативные маркеры (34, 26 и 23 единицы соответственно), тогда как Ф. Гонсалес чаще всего использует консекутивы (38), а М. Х. Азнар - экспликативы (29). Что касается особенностей употребления разных видов аргументативных маркеров в выступлении П. Санчеса, то незначительный объем его выступления (всего 2273 слова, тогда как выступления других политиков более развернуты - к примеру, выступление М. Х. Азнара насчитывает 10204 слова, Ф. Гонсалеса - 8756 слов, Л. Сапатеро - 8158 слов, М. Рахоя - 6300 слов, Л. Калво Сотело - 8472 слова).

В целом факты такого рода характеризуют каждого политика как языковую личность, и в то же время они указывают на то, какую аргументативную стратегию выбирает каждый выступающий и какие аргументативные приемы и тактики, эксплицируемые маркерами определенной семантики, он использует для достижения прагматической цели - убедить адресата (в нашем случае депутатов Конгресса Генеральных Кортесов Испании). Иными словами, выступающий/адресант может по-разному структурировать доказательную базу своих аргументативных суждений. В одних случаях более эффективно, по мнению адресанта, акцентировать внимание адресата на причинах того или иного положения дел, и он использует экспликативы (причинные маркеры). В других случаях тот же самый адресант может избрать другую тактику для достижения желаемого прагматического эффекта и сделать акцент не на причине, а на следствии - возможном (гипотетическом) или реальном, вытекающем из излагаемых им фактов и/или предположений, и тогда он прибегает к помощи иных аргументативных маркеров - консекутивов. Он также может «играть на опережение» - прогнозировать возможные возражения со стороны адресата и использовать с этой целью контрагументативы. Однако, как показывают наблюдения, в дискурсивной практике адресант никогда не использует ту или иную аргументативную стратегию в «чистом виде». Как правило, он сочетает приемы и методы разных стратегий, хотя и отдает - в большей или меньшей степени - предпочтение одной из них. Именно в этом убеждают нас приведенные факты о частотности употребления разных видов аргументативных маркеров в речи испанских политиков.

\section{Заключение}

В заключение отметим следующее. Проведенное исследование показало, что испанский политический дискурс рассматриваемого типа, протекающий в одних и тех же коммуникативно-дискурсивных условиях, имеет явно выраженный аргументативный характер и в нем широко представлены все виды аргумен- 
тативных маркеров. Наиболее частотны в нем контраргументативы, тогда как экспликативы и консекутивы менее употребительны. В то же время в исследуемом виде политического дискурса используются далеко не все средства репрезентации каждого из названных видов аргументативных маркеров, которые существуют в испанском языке. В этом проявляется влияние на аргументацию как самого политического дискурса, так и коммуникативно-дискурсивной ситуации. Вместе с тем наряду с общими закономерностями в использовании наиболее частотных и стилистически нейтральных немаркированных аргументативов выступления испанских политиков отличаются определенным выбором тех или иных аргументативных средств, что характеризует их как языковую личность. Не менее ярко языковая личность испанских политических деятелей проявляется в выборе ими той или иной аргументативной стратегии, сочетании разных аргументативных приемов и тактик. В целом проведенное исследование подтвердило, что выбор и частотность употребления разных видов аргументативов в политическом дискурсе зависят от многих факторов, в числе которых национальные культурно-специфические дискурсивные практики, тип дискурса и дискурсивные условия (ситуации) их реализации, а также языковая личность самого политика (адресанта).

\section{ЛИТЕРАТУРА}

1. Шейгал Е. И. Семиотика политического дискурса. М. : Перемена, 2000. 367 c.

2. Van Dijik T. Analisis del discurso ideologico. Separata de Version. Barcelona, 1999. Рp. 23-36.

3. Михалева О. Л. Политический дискурс: Специфика манипулятивного воздействия. М. : ЛИБРОКОМ, 2009. С. 72.

4. Гришаева Л. И. Парадоксы медиалингвистики. Воронеж : НАУКА-Юнипресс, 2014.

5. Ларионова М. В., Сливчикова Ю. В. Современная Испания : новая политическая реальность - новый политический дискурс // Вестник Том. гос. ун-та. Филология. 2019. № 59. С. 53-66.

6. Ларионова М. В. Испанский газетно-публицистический дискурс : искусство информации или мастерство манипуляции? : монография. М. : МГИМО-Университет, 2015. $327 \mathrm{c}$.

7. Guerrero Salazar S., Núñez Cabezas E. A. El lenguaje político español. Madrid : Cátedra, 2002. 555 p.

8. González Sanz M. El discurso parlamentario andaluz: estrategias argumentativas pertenecientes al plano léxico // Estrategias argumentativas y discurso politico. Madrid : Arco/Libros, 2015. Pp. 223-250.

9. Уржумиева А. О. Языковые особенности политического дискурса : на материале выступлений испанских парламентариев : автореф. дис. ... канд. филол. наук. М., 2009. 20 с.
10. Чудинов А. П. Россия в метафорическом зеркале : когнитивное исследование политической метафоры (1991-2000) : монография. Екатеринбург : Урал. гос. пед. ун-т, 2001. $238 \mathrm{c}$.

11. Будаев Э. В. Дискурсивный подход к анализу политической метафоры // Культура и текст / Алтайский государственный педагогический университет. Барнаул, 2016. № 1 (24). C. 5-19.

12. Gutiérrez $S$. Discurso político y argumentación. URL: https://www.researchgate.net/publication/251886295_ DISCURSO_POLITICO_Y_ARGUMENTACION

13. Краткий словарь по логике / под ред. Д. П. Горского. М. : Просвещение, 1991. 355 с.

14. Briz A. Los conectores pragmáticos en español. Contextos.: Gramma-Temas 2. León : Universidad de León, $1997.429 \mathrm{p}$.

15. Anscombre J. C., Ducrot O. La argumentación en la lengua. Madrid : Editorial Gredos, 1994. 248 p.

16. Ивин A. А. Основы теории аргументации. М. : ВЛАДОС, 1997. $347 \mathrm{c.}$

17. Monasterio L. Manual de Retorica Parlamentaria y Oratoria Deliberativa. Buenos Aires : Konrad, 2010. 128 p.

18. Zorraquino M., Portolés L. Los marcadores del discurso // Gramática descriptiva de la lengua española. T. III. Madrid : Espasa Calpe, 1999. Pp. 4051-4214.

19. Fuentes Rodríguez C. Operador/conector: un criterio para la sintaxis discursiva // Rilce. 2003. 19,1. Pp. 61-85.

20. Llorente M. T. Organizadores de la conversación. Salamanca : Universidad Salamanca, 1996.

21. Garrido Rodríguez M. del Camino. Conectores contraargumentativos en la conversation coloquial. León : Secretariado de Publicaciones y Medios Audiovisuales, 2004. 240 p.

22. Matte Bon F. Gramática Comunicativa del español. De la lengua a la idea. Tomo II. Madrid : Edelsa, 2005. $380 \mathrm{p}$.

23. Galán Rodríguez C. La subordinación causal y final // Gramática descriptiva de la lengua española. T. III. Madrid : Espasa Calpe, 1999. Pp. 3597-3642.

24. Álvarez A. Las construcciones consecutivas // Gramática descriptiva de la lengua española. T. III. Madrid : Espasa Calpe, 1999. Pp. 3739-3804.

\section{ИСТОЧНИКИ}

1. Discurso de investidura de Leopoldo Calvo-Sotelo Bustelo / Congreso de losDiputados, miércoles 18 de febrero de 1981.

2. Discurso de Pedro Sánchez en la segundasesión del debate de investidura / Intervención del candidato a la investidura para la Presidencia del Gobierno 26 de octubre de 2016. URL: www.psoe.es

3. Discurso de Mariano Rajoy. Sesión de Investidura 26 de octubre de 2016. URL: www.pp.es

4. Discurso de investidura de Felipe González Márquez. / Congreso de losDiputados, lunes 4 de diciembre de 1989.

5. Discurso de investidura de José María Aznar López / Congreso de losDiputados, viernes 3 de mayo de 1996. 
6. Discurso de investidura del candidato a la presidencia del gobierno, José Luis Rodríguez Zapatero / Songreso de losdiputados, 15 de abril de 2004.

\section{REFERENCES}

1. SHejgal E. I. Semiotika politicheskogo diskursa. M.: Peremena, 2000. $367 \mathrm{~s}$.

2. Van Dijik T. Analisis del discurso ideologico. Separata de Version. Barcelona, 1999. Pp. 23-36.

3. Mihaleva O. L. Politicheskij diskurs: Specifika manipulyativnogo vozdejstviya. M.: LIBROKOM, 2009. P. 72.

4. Grishaeva L. I. Paradoksy medialingvistiki. Voronezh: NAUKA-YUnipress, 2014.

5. Larionova M. V., Slivchikova YU. V. Sovremennaya Ispaniya: novaya politicheskaya real'nost' - novyj politicheskij diskurs. In: Vestnik Tomskogo gos. un-ta. Filologiya. 2019. No. 59. Pp. 53-66.

6. Larionova M. V. Ispanskij gazetno-publicisticheskij diskurs: iskusstvo informacii ili masterstvo manipulyacii?: monografiya. M.: MGIMO-Universitet, 2015. 327 p.

7. Guerrero Salazar S., Núñez Cabezas E. A. El lenguaje político español. Madrid: Cátedra, 2002. 555 p.

8. González Sanz M. El discurso parlamentario andaluz: estrategias argumentativas pertenecientes al plano léxico. In: Estrategias argumentativas y discurso politico. Madrid: Arco/Libros, 2015. Pp. 223-250.

9. Urzhumceva A. O YAzykovye osobennosti politicheskogo diskursa: na materiale vystuplenij ispanskih parlamentariev: Avtoreferat dis. ... kand. fil. nauk. M., 2009. 20 p.

10. CHudinov A. P. Rossiya v metaforicheskom zerkale: kognitivnoe issledovanie politicheskoj metafory (19912000): monografiya. Ekaterinburg: Ural'skij gos. ped. un-t, 2001. $238 \mathrm{p}$.

11. Budaev E’. V. Diskursivny’j podxod k analizu politicheskoj metafory'. In: Kul 'tura i tekst / Altajskij gosudarstvenny`j pedagogicheskij universitet. Barnaul, 2016. No. 1 (24). Pp. 5-19.

12. Gutiérrez S. Discursopolítico y argumentación. Available at: https://www.researchgate.net/publication/251886295_DISCURSO_POLITICO_Y_ARGUMENTACION

13. Kratkij slovar' po logike / pod red. D. P. Gorskogo. M.: Prosveshchenie, 1991. 355 p.

14. Briz A. Los conectores pragmáticos en español. Contextos.: Gramma-Temas 2. León: Universidad de León, 1997. 429 p.

Воронежский государственный университет

Корнева В. В., доктор филологических наук, профессор, заведующая кафедрой романской филологии

E-mail: kornevavalentina@mail.ru

Долбилова Е. В., кандидат филологических наук, доиент кафедры романской филологии

E-mail:dolbilova@rgph.vsu.ru

Поступила в редакиию 10 июля 2020 г.

Принята к публикаџии 25 сентября 2020 г.
15. Anscombre J. C., Ducrot O. La argumentación en la lengua. Madrid: Editorial Gredos, 1994. 248 p.

16. Ivin A. A. Osnovy teorii argumentacii. M.: Gumanit, izd. centr VLADOS, 1997. 347 p.

17. Monasterio L. Manual de Retorica Parlamentaria y Oratoria Deliberativa. Buenos Aires: Konrad, 2010. 128 p.

18. Zorraquino M. Portolés L. Los marcadores del discurso. In: Gramática descriptiva de la lengua española. T. III. Madrid: Espasa Calpe, 1999. Pp. 4051-4214.

19. Fuentes Rodríguez C. Operador/conector: un criterio para la sintaxis discursiva. In: Rilce. 2003. 19,1. Pp. 6185.

20. Llorente M. T. Organizadores de la conversación. Salamanca: Universidad Salamanca, 1996.

21. Garrido Rodríguez M. del Camino. Conectores contraargumentativos en la conversation coloquial. Leon: Secretariado de Publicaciones y Medios Audiovisuales, 2004. 240 p.

22. Matte Bon F. Gramática Comunicativa del español. De la lengua a la idea. Tomo II. Madrid: Edelsa, 2005. 380 p.

23. Galán Rodríguez C. La subordinación causal y final. In: Gramática descriptiva de la lengua española. T. III. Madrid: Espasa Calpe, 1999. Pp. 3597-3642.

24. Álvarez A. Las construcciones consecutivas. In: Gramática descriptiva de la lengua española. T. III. Madrid: Espasa Calpe, 1999. Pp. 3739-3804.

\section{SOURCES}

1. Discurso de investidura de Leopoldo Calvo-Sotelo Bustelo / Congreso de losDiputados, miércoles 18 de febrero de 1981/

2. Discurso de Pedro Sánchez en la segundasesión del debate de investidura / Intervención del candidato a la investidura para la Presidencia del Gobierno 26 de octubre de 2016. Available at: www.psoe.es

3. Discurso de Mariano Rajoy. Sesión de Investidura 26 de octubre de 2016. Available at: www.pp.es

4. Discurso de investidura de Felipe González Márquez / Congreso de losDiputados, lunes 4 de diciembre de 1989.

5. Discurso de investidura de José María Aznar López / Congreso de losDiputados, viernes 3 de mayo de 1996.

6. Discurso de investidura del candidato a la presidencia del gobierno, José Luis Rodríguez Zapatero / Songreso de losdiputados.

Voronezh State University

Korneva V. V., Doctor of Philology, Professor, Head of the Romance Philology Department

E-mail: kornevavalentina@mail.ru

Dolbilova E. V., Candidate of Philology, Associate Professor of the Romance Philology Department

E-mail:dolbilova@rgph.vsu.ru

Received: 10 July 2020

Accepted: 25 September 2020 


\section{Для цитирования:}

Корнева В. В., Долбилова Е. В. Аргументативные маркеры в испанском политическом дискурсе // Вестник Воронежского государственного университета. Серия: Лингвистика и межкультурная коммуникация. 2020. № 4. C. 87-97. DOI: https://doi.org/10.17308/lic.2020.4/3083

\section{For citation:}

Korneva $V$. V., Dolbilova E. V. Argumentative markers in the Spanish political discourse. Proceedings of Voronezh State University. Series: Linguistics and Intercultural Communication. 2020. No. 4. Pp. 87-97. DOI: https://doi. org/10.17308/lic.2020.4/3083 